\title{
УГРОЗЫ И РИСКИ БЕСПРОВОДНЫХ СЕТЕЙ 5G. ИЗМЕРИТЕЛЬНЫЙ АСПЕКТ
}

\author{
Дымова И.А.
}

Продолжсается обсуждение проблем, связанных с повсеместным переходом в области телекоммуникаций на пятое поколение беспроводньх сетей связи (5G). Внимание акиентируется на анализе хода и результатов экспертиз, которые были заявлены в некоторых странах для прояснения вопросов, касающихся безопасности нового поколения телекоммуникационных сетей для здоровья человека и окружающей среды. В поле зрения - ситуация в Швейцарии, России, Франциии и США.

DOI: $10.20537 /$ mce2021econ12

Введение. В работе продолжается обсуждение проблем, связанных с повсеместным переходом в области телекоммуникаций на сети $5 \mathrm{G}$, см. [1]. Ситуация с переходом на сети $5 \mathrm{G}$ оценивается с точки зрения степени безопасности этой инновационной технологии для здоровья человека и окружающей среды.

Один из основных выводов проведенного в [1] анализа состоял в необходимости разобраться в результатах экспертиз, которые были анонсированы в ряде случаев развертывания сетей 5G. Имелись в виду дополнительные исследования по безопасности сетей $5 \mathrm{G}$ для населения, намеченные к проведению в Швейцарии и России. В данной статье список пополняется соответствующими материалами по Франции, а также США.

О ходе и основных результатах экспертиз в отношении угроз и рисков для здоровья человека и живой природы от беспроводных сетей $5 G$.

Швейцария. Швейцария была лидером среди европейских государств по внедрению сетей $5 \mathrm{G}$, она первой в Европе (и третьей в мире) ввела в коммерческую эксплуатацию сеть 5G (апрель 2019 г.) — два ведущих мобильных оператора Швейцарии запустили в коммерческую эксплуатацию сеть $5 \mathrm{G}$ в 54 ее городах (государственная компания Swisscom) и 150 муниципалитетах (компания Sunrise). До конца 2019 г. 
компания Swisscom должна была ввести в эксплуатацию сеть 5G уже на 90\% территории Швейцарии.

Однако сразу же после пилотных запусков парламенты некоторых кантонов федеративной структуры страны (Женева, Во, Невшатель и Юра) по инициативе «партии зеленых» проголосовали за приостановку выдачи разрешений на введение в эксплуатацию новых вышек мобильной связи 5G до тех пор, пока не будет готов правительственный отчет о безопасности их излучения [2] (здесь и далее используются данные швейцарского иновещания swissinfo). Противодействие сетям 5G ожидалось еще от ряда субъектов федерации. Опросы населения свидетельствовали, что $65 \%$ населения франкоговорящей Швейцарии опасаются негативного влияния на состояние их здоровья от 5G (на общенациональном уровне - 54\%).

Летом и осенью 2019 г. проходили массовые выступления противников развертывания сетей 5G. Отвечая на критику, федеральное правительство Швейцарии одобрило запуск инициативы под названием «За экологически безопасную и энергоэффективную мобильную связь», введя ее своим решением, вступившем в силу после публикации 15 октября 2019 г., в «Федеральной газете» (нем. Bundesblatt).

В первую очередь текст Решения содержал предписание никоим образом не увеличивать предельные допустимые уровни (ПДУ) излучения от мобильных сетей, установленные действующим на тот момент Постановлением о защите от неионизирующего излучения.

Предусматривалось также:

- проведение четкого разделения между использованием мобильной телефонии и интернет-услуг внутри и вне помещений (в частности, в помещении Интернет должен был раздаваться операторами только по волоконно-оптическим или коаксиальным кабелям);

- получение мобильными операторами, планирующими установить новые антенны или же увеличить мощность существующих, письменного согласия местных жителей, проживающих от новой или модернизированной антенны в радиусе 400 метров;

- обеспечение свободного доступа к консультационным центрам для людей, особо чувствительных к электромагнитному излучению.

Решение допускало возможность проведения общенационального референдума о будущих параметрах развития сетей $5 \mathrm{G}$ в Швейцарии. Для этого сторонникам упомянутой выше инициативы предлагалось до 
15 апреля 2021 г. собрать 100 тыс. подписей жителей страны, поддерживающих идею проведения такого референдума.

Однако эксперты из правительственной комиссии Швейцарии (создана в 2018 г.) не смогли согласовать однозначные рекомендации насчет мер по ограничению возможного вреда от излучения $5 G$ на здоровье людей (swissinfo от 29 ноября 2019 г.). В результате в отчете правительству о безопасности было только рекомендовано предоставлять больше информации общественности о не подтвержденных опасениях о возможных негативных последствиях от электромагнитного излучения, а также проводить больше исследований о возможных рисках для здоровья, связанных с технологиями мобильной связи.

При этом, как отметило в том же сообщении swissinfo, «швейцарские мобильные операторы Swisscom, Sunrise, а также Salt, чьи представители были представлены в экспертной группе, истолковали отчет в свою пользу, выразив удовлетворение выводами экспертов и заявив, что «ничто не мешает развертыванию $5 \mathrm{G}$ с точки зрения охраны здоровья».

Напротив, министр местного самоуправления Женевы А. Ходжерс в интервью swissinfo выразил разочарование по поводу неубедительного характера отчета, заявив, что Женева сохранит мораторий на расширение сети $5 \mathrm{G}$ в ожидании «менее технического и более политического ответа со стороны федерального правительства».

По состоянию на конец декабря 2020 г. федеральное правительство Швейцарии так и не выпустило каких-либо других руководящих указаний по поводу 5G. При этом несколько кантонов Швейцарии продолжали сохранять свой мораторий на расширение сетей $5 \mathrm{G}$, предусматривающий запрет на введение в эксплуатацию новых вышек сотовой связи этого стандарта.

В то же время операторы мобильной связи продолжали строительство и расширение своих сетей $5 \mathrm{G}$ с целью обеспечить полное покрытие Швейцарии, хотя и не везде могли из-за моратория кантонов запускать новые вышки в эксплуатацию.

Новый виток в развитии ситуации с сетями $5 \mathrm{G}$ в Швейцарии начался весной 2021 г. Так, 1 марта было сообщено, что Федеральное министерство окружающей среды, транспорта и коммуникаций завершило разработку нормативных рекомендаций в области предельных параметров излучения антенн мобильного интернета $5 \mathrm{G}$, построенных на принципах адаптивной антенной решетки [3]. Сообщалось также, что 
Министерство опубликовало для кантонов, а также для органов власти муниципального уровня инструкции [4] относительно эксплуатации таких антенн.

В этих инструкциях, в частности, говорилось, что, с одной стороны, предельные, признанные «безопасными», частотные параметры излучения антенн останутся прежними и ослаблены не будут. С другой стороны, власти делают все, чтобы успокоить всех, кто еще скептически настроен в отношении $5 \mathrm{G}$, и, самое главное, снять сомнения общин и муниципалитетов, все еще выступающих против массового монтажа соответствующей коммуникационной инфраструктуры. Поэтому теперь 8 разных регионах и кантонах замеры лучевой нагрузки и оценка степени и характера воздействия излучения новых антенн на людей и природу смогут производиться по-разному. Соответственно, и критерии выдачи соответствующих лищензий, допусков и сертификатов соответствия будут формулироваться в зависимости от региона по-разному.

Следует отметить, что новые нормативные и руководящие принципы в области развития беспроводных сетей в Швейцарии были восприняты участниками процесса неоднозначно.

Так, по словам министра коммуникаций и окружающей среды C. Соммаруги, эти новые принципы «гарантируют населению полную безопасность, одновременно способствуя дальнейшему движению страны по пути внедрения современных цифровых технологий». Швейцарская Ассоциация предприятий телекоммуникационной сферы (Schweizerischer Verband der Telekommunikation) также приветствовала новые решения, ожидая быстрого разблокирования процесса внедрения новых технологий.

Однако с таким выводом не согласны представители общественной Ассоциации противников излучения антенн мобильного интернета (Verein Schutz vor Strahlung), утверждая, что «новые инструкиии властей являются скрытым повышением допустимых предельных норм излучения» [3]. Основанием для такого вывода являлось то, что в новых инструкциях в принципе допускалась более интенсивная работа антенн базовых станций, если средние значения интенсивности излучения в течение 6-и минут не будут превышать предельные уровни (в противном случае должен был срабатывать встроенный в антенны ограничительный механизм). 
Тем не менее, противники 5G из названной выше Ассоциации сделали вывод о имеющем место некотором трюке, связанном с подменой понятий, и что в результате «это приведет к реальному увеличению степени лучевой нагрузки» [3].

Окончательный вывод о том, насколько властям действительно удастся разблокировать процесс внедрения в Швейцарии систем 5G, в [3] остался под вопросом. Предрекались судебные прочессы, в ходе которых новые нормы по электромагнитному излучению антенн должны получить правовую оценку и т.n. Вопрос о проведении в Швейцарии упоминаемого выше общенационального референдума о запрете сетей 5 н не вставал.

Россия. В нашей стране первые сети 5G были развернуты осенью 2019 г. в Кронштадте, а затем в Москве. В отличие от Швейцарии и ряда других локаций, это не сопровождалось массовыми протестными выступлениями противников сетей 5G. Однако ситуация была достаточно дискуссионной. Во-первых, с точки зрения степени опасности от них здоровью населения. Но еще более, из-за нехватки в России наиболее предпочтительных радиочастот для развертывания сетей $5 \mathrm{G}$, поскольку они уже используются российскими силовыми структурами (радиочастоты, близкие к 3.8 ГГц) [5]. Сдвиг же в более коротковолновый спектр должен привести к более высоким уровням излучательной нагрузки, соответственно могут быть превышены предельно допустимые уровни излучения и нарушены действующие санитарно-эпидемиологические правила и нормы (СанПиНы), что нежелательно.

Считается, что Россия относится к числу стран с наиболее жесткими ограничениями на ПДУ электромагнитного излучения (10

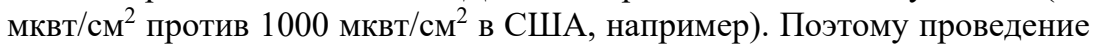
исследований по уточнению реальных уровней излучения от сетей $5 \mathrm{G}$ может быть выгодно и сторонникам 5G, поскольку можно допустить, что результаты таких исследований позволят ослабить жесткость ограничений на ПДУ (забегая вперед, отметим, что в случае с Россией, объявлен именно такой результат).

В конце января 2020 г. на сайте правительства Москвы появилась информация о том, что в столице проведут исследование о влиянии сетей сотовой связи «на благополучие горожан и городскую среду» [6].

Исследование было инициировано Департаментом информационных технологий (ДИТ) правительства Москвы и одобрено Министер- 
ством цифрового развития РФ, Минздравом РФ и рабочей группой программы «Цифровая экономика». На проведение работы был объявлен конкурс, который выиграл НИИ медицины труда имени Н.Ф. Измерова РАМН (НИИ МТ). Результаты исследования должны были быть представлены экспертам в первом квартале 2021 г. и направлены в Минздрав РФ и Роспотребнадзор (предыдущие исследования по изучению влияния ЭМП на организм человека проводились также в НИИ МТ, в начале 2000-х гг., их результаты были положены в основу действующих санитарно-эпидемиологических норм [6]).

В начале июня эта информация подтвердилась и конкретизировалась [7]. «В ходе нынешнего исследования должно быть изучено влияние на здоровье человека сотовой связи поколений $2 \mathrm{G}-5 \mathrm{G}$ в диапазоне частот 450 МГц - 43.5 ГГц. Так, должен быть установлен предельно допустимый уровень излучения, соответственно планируется протестировать сотовую связь в полевых и лабораторных условиях, в том числе исследовать воздействие создаваемого излучения на подопытных животных (это крысы-самцы весом 180-200 г). Эксперимент продлится полгода. Полученные данные могут быть использованы для оценки актуальности и возможного пересмотра принятых норм по электромагнитному излучению. На их основе Минздрав РФ и Роспотребнадзор должны будут принять решение относительно необходимости усовершенствования правил эксплуатации сотовых систем и пересмотра гигиенических норм их излучения» [7].

Первые публикации о предварительных результатах исследования появились в СМИ в конце января 2021 г. [8]. Отмечалось, что «ученые НИИМТ им. Измерова по результатам исследования безопасности мобильной связи всех стандартов, в том числе $5 \mathrm{G}$, пришли к выводу о возможности увеличения максимально допустимого уровня электромагнитного излучения базовых станциий» (выделено автором настоящей статьи).

Отмечалось также, что «материалы исследования направлены на экспертное обсуждение членам рабочей группы, состоящей из представителей федеральных органов власти, научно-исследовательских организаций и операторов связи. Окончательные результаты научноисследовательской работы будут утверждены по его итогам». Особо подчеркивалось, что «пересмотр нормативов будет способствовать ско- 
рейшему развитию сетей связи нового поколения и появлению высокоскоростных сервисов для жителей городов и бизнеса».

В [8] сообщалось, что «НИР состояла из трех этапов, лабораторная часть исследования являлась завершающим этапом. В рамках этого этапа специалисты провели в дневное и вечернее время полевые измерения уровней ЭМП в шести типовых микрорайонах Москвы, где представлены стандарты связи 2G-4G, а также в пилотных зонах 5G. Лабораторные измерения проводились в течение пяти месяцев, в соответствии с российскими и международными стандартами и методиками. В результате был определен безопасный уровень электромагнитного излучения при перспективном использовании базовых станций стандарта $5 \mathrm{G}$, в том числе в миллиметровых частотах, таких как 28 ГГц и 37 ГГц.»

В сообщении цитировались слова замруководителя ДИТ Москвы А. Горбатько о том, что проведенное исследование показало, что электромагнитные излучения сотовой связи являются безопасными.

Завершающей на данный момент публикацией о результатах исследования, проведенного в НИИ медицины труда, можно считать сообщение ТАCC [9] в конце мая о предложении экспертной комиссии изменить в России предельно допустимый уровень (ПДУ) электромагнитного излучения от беспроводных сетей. А именно, предлагается по-

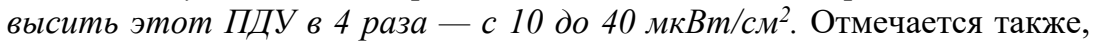
что по результатам исследования ученые предложили более современную и точную методику измерения электромагнитного поля, создаваемого базовыми станциями систем сотовой связи, и сделали вывод о необходимости внедрения новых методов контроля уровня электромагнитных полей.

Результаты исследования были направлены в Минздрав России и Роспотребнадзор для принятия окончательных решений.

Франция. 22 апреля 2021 г. на официальном сайте Российского национального комитета по защите от неионизирующего излучения (РНКЗНИ) появилось сообщение [10] об открытии Агентством по вопросам пищевых продуктов, окружающей среды, гигиены и безопасности труда (ANSES) Франции Общественного обсуждения экспертного отчета «Воздействия электромагнитных полей технологии $5 G$ и возможных связанных с этим последствий для здоровья».

Согласно [10], Экспертный отчет и заключение относительно технологии $5 \mathrm{G}$ и рисков для здоровья были подготовлены по запросу ми- 
нистерства здравоохранения Франции. Работа проводилась специализированной экспертной группой ANSES «Технологии 5G» по оценке последствий для здоровья, связанных с развертыванием 5G. В группу были включены исследователи различных специальностей.

В отчете представлены выводы относительно рисков для здоровья и рекомендации по оценке воздействия и потребности в исследованиях. Отмечалось также, что согласно принятому протоколу, все комментарии, сделанные в процессе Общественного обсуждения, должны стать предметом систематического и подробного анализа ANSES. A после консультаций с общественностью рабочая группа «Технологии 5G» проанализирует соответствующие комментарии и в рамках процедур экспертной оценки Агентства при необходимости дополнит отчет коллективной оценкой. Затем итоговый отчет и заключение будут опубликованы в соответствии с обычными процедурами Агентства.

Более подробной информации о ходе Общественного обсуждения упомянутого выше французского экспертного отчета и его результатах пока нет. Однако уже и из изложенного можно заключить, что у широкой общественности Франции должно быть значительно больше возможностей поучаствовать в выработке общественного мнения по столь острой и неоднозначной проблеме как широкомасштабное развертывание сетей $5 \mathrm{G}$, чем в ряде других стран, в том числе и в России.

Заключение. Проблемы, связанные с рисками от использования сетей $5 \mathrm{G}$, нельзя признать решенными.

Следует принять к сведению мнение об обсуждаемом исследовании НИИ МТ им. Измерова по беспроводным сетям, которое на начальной стадии его проведения было высказано одним из наиболее авторитетных российских радиобиологов. А именно, Председатель РНКЗНИ, доктор биологических наук О. Григорьев (является также членом научно-консультативного комитета ВОЗ по электромагнитным полям) в интервью [11], говоря о перспективах новой технологии в Москве, обратил внимание на то, что «Институт медицины труда, который мэрия выбрала подрядчиком исследования 5G, вряд ли адекватно справится - из-за недостатка времени, кадров, финансирования и огрехов в самом техническом задании...». И подчеркнул, что «эта научно-исследовательская работа - тема для серьезного анализа, так как плавно продвигаются идеи по ухудшению условий для населения страны, заведомо повышающие риски развития заболеваний» [11]. 
В связи с этим хотелось бы отметить, что при знакомстве с материалами по проведению экспертиз относительно безопасности беспроводных сетей для здоровья населения и окружающей среды все-таки складывается впечатление, что приоритетной задачей экспертных групп являлось, как правило, обоснование допустимости смягчения ограничений на ПДУ электромагнитного излучения от беспроводных сетей.

В таком смягчении заинтересованы производители, поскольку при этом могут быть существенно сокращены производственные затраты на разворачивание сетей $5 \mathrm{G}$, но это, скорее всего, усугубит ситуацию с рисками для здоровья человека и живой природы.

Следует также отметить недавнее сообщение на сайте РНКЗНИ о том, что в США базовые предельные уровни электромагнитного поля радиочастот должны быть пересмотрены на основании окончательного судебного решения в пользу сторонников безопасности беспроводной связи [12].

Согласно сообщению [12], 13 августа 2021 г. Федеральный суд США принял окончательное решение о необходимости пересмотреть базовые нормативы электромагнитного поля радиочастот в стране. Это решение должно быть обязательно исполнено Федеральной комиссией по связи США (FCC), которая устанавливает предельные уровни радиочастот для средств беспроводной связи, в том числе для базовых станций сотовой связи, включая перспективные системы $5 \mathrm{G}$.

В постановлении суда констатируется, что FCC не отреагировала на «научные доказательства того, что воздействие радиочастотного излучения со значениями ниже текущих предельных уровней, может вызвать негативные последствия для здоровья, не связанные с раком». В [12] отмечается, что суд установил, что FCC «не представила аргументированного объяснения своего утверждения о том, что ее руководящие принципы адекватно защищают от вредного воздействия радиочастотного излучения». Также в решении суда определяется, что Управление по санитарному надзору за качеством пищевых продуктов и медикаментов (FDA) не проводило анализа соответствующих научных результатов, а представила свои выводы в поддержку предельно-допустимых уровней FСС США без объяснения причин.

Инициатором этого судебного иска стал Environmental Health Trust (Фонд здоровой окружающей среды), к которому присоединился ряд общественных организаций США. По словам Президента этого Фонда, 
доктора Д. Дэвис, «5G никогда бы не выпустили на рынок, если бы FCC объективно рассмотрело накопленные научные данные». Инициаторы судебного иска планируют организовать слушания в Конгрессе США.

В [12] отмечается также, что «решение суда в США может иметь долговременные международные последствия, так как существует тесная связь между обязательными предельными уровнями электромагнитного поля радиочастот Федеральной комиссии связи США и добровольными коммерческими стандартами, на которые ориентированы производители оборудования связи различных стран... кроме того, возникло серьезное основание для множества судебных дел о вреде здоровью, обусловленном избыточным электромагнитным облучением при доверии потребителя к декларируемой безопасности сотовых телефонов».

Таким образом, следует констатировать, что окончательные выводы делать пока преждевременно.

\section{СПИСОК ЛИТЕРАТУРЫ}

1. Дымова И.А. К Вопросу о развертывании сетей беспроводной связи пятого поколения (5G). Угрозы и риски// Анализ и моделирование экономических и социальных процессов / Математика. Компьютер. Образование: Сб. научн. трудов. Выпуск 27. - М.-Ижевск: НИЦ «Регулярная и хаотическая динамика», 2020. DOI: 10.20537/mce2020econ10

2. Мизере М.-А. Как Швейцария сопротивляется введению связи формата $5 \mathrm{G}$. URL: https://www.swissinfo.ch/rus/за-связь-без-брака_как-швейцариясопротивляется-введению-связи-формата-5g/44944496

3. Швейцария сделала еще один шаг к сетям 5G? URL:

https://www.swissinfo.ch/rus/швейцария-сделала-еще-один-шаг-к-сетям-5g/46396452/

4. Mobilfunk: Die Vollzugshilfe für den Umgang mit adaptiven Antennen ist bereit. URL: https://www.bafu.admin.ch/bafu/de/home/dokumentation/medienmitteilungen/anzeigensb-unter-medienmitteilungen.msg-id-82401.html

5. Частота 5G сетей в России и в мире - все диапазоны. URL: https://5grussia.ru/chastota-5g-setej-v-rossii-i-v-mire-vse-diapazony

6. Новый стандарт связи: в столице проверят безопасность 5G-сетей. URL: https://www.mos.ru/news/item/68802073/

7. Российские ученые оценят опасность излучения $5 \mathrm{G}$ на крысах. URL: https://www.vedomosti.ru/technology/articles/2020/06/03/831780-rossiiskieuchenie-otsenyat-izlucheniya-5g 
8. Представлены предварительные результаты исследования безопасности 5G // ДИТ Москвы. URL: https://www.interfaxrussia.ru/moscow/news/predstavleny-predvaritelnye-rezultaty-issledovaniyabezopasnosti-5g-dit-moskvy

9. Ученые подтвердили безопасность электромагнитного поля от станций связи 5G в Москве. URL: https://yandex.ru/turbo/tass.ru/s/moskva/11474795

10. Общественное обсуждение экспертного отчета «Воздействия электромагнитных полей технологии $5 \mathrm{G}$ и возможных связанных с этим последствий для здоровья» открыто Агентством по вопросам пищевых продуктов, окружающей среды, гигиены и безопасности труда (ANSES) Франции. URL: http://emf-net.ru/index.php?id=250

11. Главный российский радиобиолог: COVID мог появиться как мутация от излучения 5G. URL:

https://octagon.media/istorii/glavnyj_rossijskij_radiobiolog_covid_mog_poyavit sya_kak_mutaciya_ot_izlucheniya_5g.html

12. Базовые предельные уровни электромагнитного поля радиочастот в США должны быть пересмотрены на основании окончательного судебного решения в пользу сторонников безопасности беспроводной связи. URL: http://www.emf-net.ru/index.php?id=258

\section{THREATS AND RISKS OF 5G WIRELESS COMMUNICATION NETWORKS. MEASUREMENT ASPECT}

\section{Dymova I.A.}

The paper presents a discussion of the problems associated with the widespread transition in the field of telecommunications to the 5th generation of wireless communication networks (5G). Attention is focused on the analysis of the progress and results of the examinations that were announced in some countries to clarify issues related to the safety of a new generation of telecommunications networks for human health and the environment. An overview of the situation in Switzerland, Russia, France and the USA is given. 